\title{
“Chameleon” Meets Soul Train: Herbie, James, Michael, Damita Jo, and Jazz-Funk
}

\author{
Steven F. Pond
}

Herbie Hancock must have felt great when he and his group, the Headhunters, gave a live performance of their hit song "Chameleon" on the weekly television show Soul Train, airing September 28, 1974. Released late the previous year, "Chameleon" and the album for which it was the lead single (Head Hunters $)^{1}$ were enjoying an extended ride on the pop, rhythm and blues (R\&B), and jazz charts. Head Hunters and the follow-up album, Thrust (1974), would become foundational to the jazz-funk movement throughout the 1970s. " "Chameleon" in particular gave listeners plenty of reason to rethink just how separate funk and jazz were or needed to be. However, to a percentage of Hancock's mainstream jazz fans, as well as a cadre of jazz critics and scholars, the music represented a strange turn. Throughout the better part of the 1960s, Hancock had solidified a kind of Mount Rushmore position in jazz circles as the pianist in Miles Davis's "second great quintet," considered then (and since) to be one of the most influential small jazz groups in history. Hancock had gone on to form an avant-garde jazz group: the Herbie Hancock Sextet (later Septet), known colloquially as the Mwandishi group, after Hancock's Swahili sobriquet, loosely translated as "composer." Now, with "Chameleon's" extended groove, hundreds of thousands of young, platform-soled funk fans were listening - and dancing - to a kind of jazz that discomfited many of their seated predecessors. Overall sales figures for the single and the album were stunning. Industry sales charts made a convincing statement about "Chameleon's" popularity, whether 
tagged as jazz, pop, or R\&B. But a significant measure of its validity as funk came from the dancing bodies on "the hippest trip in America." 3

In an earlier work, I explored "Chameleon" and the album Head Hunters from several intersecting points of view. ${ }^{4}$ The central dilemma for jazz critics and fans was how to reconcile the music's funkiness with its jazz identity, an identity for which there was a decided lack of consensus. This dilemma became dramatized when Head Hunters rose to the near top of the newly christened Billboard Jazz Albums chart while "Chameleon" likewise rode the crest of the R\&B Singles chart (the chart home for funk releases at the time). Record sales marketing and the charts they fostered were affected by radio airplay formats; public-radio jazz stations had little attraction to album cuts from Head Hunters at first, but "black urban" and "free-form" radio embraced "Chameleon." Nevertheless, the album had been issued initially through jazz store outlets, and album sales were tracked on this basis. Soon enough, record bins in the R\&B, soul, and funk sections of the stores sported the album, in addition to its placement in the jazz racks. Who could tell whether the purchaser was, in fact, a jazz customer as opposed to a funk customer (as if the two could not exist in a single body)? Several jazz critics resisted the album on the basis of its not being jazz, despite its overwhelming impact on the jazz chart; perhaps a new, younger, and less category-bound jazz audience was emerging. ${ }^{5}$ Yet the album was not regarded as precisely funk either, including by Hancock himself. Endeavoring to create a funk album, not a jazz one, Hancock fortuitously "decided to pay attention to the way things were flowing and not just stick to what [he] originally had in mind." ${ }^{\prime 6}$ The musical result fit precariously into a set of contested categorical terms: jazz-rock, funk-jazz, fusion jazz, and others, offered up by fans and critics to both describe the music and set stylistic boundaries for exclusivity and inclusivity.

While I explored Hancock's album largely through the lens of jazz studies in my earlier work, in this paper I consider "Chameleon" and Head Hunters from their collective perception as funk; I view the Soul Train performance as a metaphoric goal for Herbie Hancock. Hancock wanted to reconnect, through his new direction, with a young, hip, black listenership that had largely come to yawn at jazz. Reception, in the forms of critical exposure, record sales, radio airplay, and the like, could be measured through sales charts, ticket sales, and other concrete measures. But an equally solid qualitative measure of "Chameleon's" penetration into its target funk audience could be seen in its validation on that Los Angeles-based Soul Train broadcast, the most visible space for vetting funkiness in its day.

Funk dance drove the inspiration for Hancock's new musical turn, as well as the formation of his new band, the Headhunters. "Chameleon" and other songs from the album were explicitly created for dance, recalling - but far exceeding-Hancock's own history with the soul jazz idiom of the early 1960s. "Jazz-funk," as some preferred to call the Headhunters' music, seemed to signal an important reconnection of jazz and youth culture-black youth culture- 
through dance. And, to be sure, funk artists of the 1970s often came from the ranks of jazz musicians. It is not my purpose here to sketch a history of jazz musicians who played funk or vice versa, nor do I plan to rehash Head Hunters' success in bridging a funk/jazz sales gap. Rather, I want to focus on the importance of dancing in funk, Soul Train's authenticating role as a site of black youth culture, and the entwinement of funk dancing with what would become the best-selling jazz album of its time. ${ }^{7}$ I trace this entwinement through a series of topical pivots: from "Chameleon's" creation to the Robot, from the Robot to the Soul Train Line, from the Line to its dancers, to their impact on funk, to dance as a mode of connecting with jazz and funkiness, and, finally, to dance's authentication of "Chameleon."

\section{Wattstax and the Robot}

"Chameleon" owed its beginnings to the Wattstax Festival, an August 1972 concert organized by the Stax record label to memorialize the Watts riots seven years earlier. A major cultural event, the concert is remembered as the "African American Woodstock." Among the 100,000 estimated attendees, dancing was a major part of the experience. One of these attendees was Bennie Maupin, the multireed instrumentalist who had played on Miles Davis's Bitches Brew album, had later played an integral role in Herbie Hancock's "Mwandishi" avant-garde jazz ensemble, and was now the sole holdover from that group in the new band that Hancock was forming. Maupin would cowrite "Chameleon" with Hancock, along with bassist Paul Jackson and drummer Harvey Mason; Maupin supplied the jerkily syncopated melody line. "I wrote that melody [to "Chameleon"] as the result of going to see the Wattstax concert in Los Angeles," Bennie Maupin explained to me. "I was just looking at these kids. When the music started playing, everybody would start doing the Funky Robot. . . . And I started to hear in my mind melodies centered around that kind of movement." " Maupin's attraction to the Robot was not just for melodic inspiration. Hancock had recently disbanded his "Mwandishi" group and was now redirecting his efforts. Head Hunters was to be a funk, not a jazz, album. ${ }^{9}$

If the album was meant to be funk, it would have to be marketed in a funk way, to reach a funk audience, played over radio formats variously shaped and purveyed as "soul," "R\&B," "black," "urban," and "adult contemporary." It would be sold first through black neighborhood mom-and-pop stores and R\&B sections in larger, regional chain stores. Only when its sales potential was ensured would it enter the hype stream of wholesale distribution. It had gathered the momentum to propel it to platinum-designated success. ${ }^{10}$ But before that success could be possible, Hancock would have to pass a funkiness threshold: if vinyl was to be sold, the music had to be danced to in the funk styles of the day. ${ }^{11}$

The process of composing the album's material as a whole, primarily by Hancock, with significant contributions from the rest of the Headhunters, ex- 
tended the kind of linkage of music to dance that Bennie Maupin described. The band would jam at rehearsals, which were usually recorded; then, sifting through the improvised moments for the best bits, the band would sometimes re-create, sometimes adapt these strands into something cohesive, a framework on which to drape new melodies, new grooves, and new sounds in the moment:

We'd take a gig, someplace like the Lion's Share over in Marin [County, near San Francisco]. . . . So we rehearsed and got enough tunes together that we could play for least one evening. And we'd come up and just try the music out on the public. ... And those weekends were very good for us, because we got to get the feedback from the audience. ${ }^{12}$

What was that feedback? It was dancers getting sweaty on the dance floor. Remembering those weekend gigs, Hancock described Bay Area audiences-"I mean, they listen to what's going on. They listen to the groove, they listen to the solos"- and how they reacted - "And they were dancing to it. Oh, they loved it. They danced to it." The Headhunters were thriving on the creative, immediate give-and-take of dancers commenting on their music. "And so, that really inspired us and encouraged us. And it really shaped - it helped us shape the music, to refine what it was that we were doing." 13

\section{The Robot and the Soul Train Line}

Bennie Maupin saw kids dancing the Robot in August 1972 at Wattstax. The dance was already in circulation then and had been since before the beginning of the decade. ${ }^{14}$ Certainly, the Robot had taken on enough importance by late summer of the next year, when Head Hunters was recorded, that Maupin's mapping of the melody of "Chameleon" onto the dance movements gained critical traction for the song - and, likewise, the recording's jerkily syncopated line added reciprocal momentum to the Robot's popularity. ${ }^{15}$ The Robot's own breakthrough moment happened on the nationally syndicated dance show Soul Train in the fall of 1973, just prior to the release of "Chameleon," with Michael Jackson's performance of it on the Jackson 5's "Dancing Machine." Instantly, the Robot became the dance to master.

In key urban markets across the country, black teenagers and young adults were, as usual, glued to their televisions; the weekly dance show was something of a cultural imperative ${ }^{16}{ }^{2}$ Rickey Vincent's reminiscence, "Everyone got up on Saturday mornings to watch Soul Train, 'the hippest trip in America,' the black answer to American Bandstand, and a cultural mecca for the entire decade of the seventies," is inscribed time and again in assessments of Soul Train's impact on black youth. ${ }^{17}$ Patterned somewhat on the format of American Bandstandbut also on a plethora of local dance shows of the 1960s-Soul Train's signal difference lay in the presence of exclusively African American teenagers on 
the dance floor and on the bandstand. ${ }^{18}$ Soul Train's influence cut both ways. ${ }^{19}$ Guest artists understood that getting over with the Soul Train Gang (as the studio teenaged dancers were known) and making them work on the dance floor translated to acceptance in the high school and dance club, and financial success at the record shop. ${ }^{20}$ "[L] anding a Soul Train guest shot," cultural historian Kevin Phinney writes, "was tantamount to winning Amateur Night at Harlem's Apollo Theater. In the years preceding MTV and BET, Soul Train became the one appearance every R\&B act had to make, and, eventually, all the single name celebrities showed up, including Aretha, Marvin, Diana, Smokey, and Tina." ${ }^{21}$ The effect went deep, in realms of both culture and commerce. Brian Ward reports that

[b]y the end of 1973, CBS [Records] had secured a 15 per cent share of the black music business. By the end of the decade it had 125 black acts on its books and had hired a whole slew of energetic black executives and representatives like [Logan] Westbrooks, LeBaron Taylor and Vernon Slaughter, all of whom were committed to breaking CBS's black products as widely as possible. By 1979, black music accounted for about a quarter of all CBS record sales.

"One reason for CBS's extraordinary success," Ward continues, "was the fact that in 1973 the CBS-TV network acquired the nationwide syndication rights for Don Cornelius's increasingly popular Soul Train show."22

The Jackson 5's thrilling stage presence centered on their choreographed moves, an extension of the choreography made famous by earlier Motown acts, like the Temptations, Gladys Knight and the Pips, and the Four Tops. On November 3, 1973, the group lip-synched their latest hit, "Dancing Machine." (The segment can be seen via YouTube. ${ }^{23}$ At the center of the segment's action is the group's front man, Michael Jackson's (then seventeen years old), singing, spinning, and dancing solo style. His lyrics express excited astonishment over a girl whose "superbad" dancing moves are beyond human attainment-a dancing machine - while the rest of the group moves in exhilarating precision, with crossover steps, funky chicken moves, and the like. Although the verse and performance style treat "machine" metaphorically, ${ }^{24}$ Michael, at the horn break (1:18), seems to take on an actual dancing machine persona as he goes into an electrifying solo dance segment of the Robot. Coming out of a spin, Michael's expression goes deadpan, like an actor snapping into character, his back now ramrod straight, his limbs rigid, his movements isolated to his joints, as if worked by pulleys and levers inside his frame. Making the slightly jerky and random movements of a primitive mechanical man or marionette demonstrating its capacity for movement at a sideshow ${ }^{25} \mathrm{Jackson}$ at one point seems to move across the floor as if on wheels while standing in a rigidly static posture. As the break ends and Jackson falls back into line to continue the song with the 
rest of the group (1:35), cheers from the dancers ring out, inadvertently captured on an offstage mic $(1: 38){ }^{26}$

The performance caused a sensation. ${ }^{27}$ In short succession, Robotinfluenced dances, such as the Campbellock (or Locking), Waving, Popping, and the Electric Boogaloo emerged on the West Coast and, by mid-decade, Breakdancing on the East Coast. ${ }^{28}$ These dances became key moves for performance - on prosceniums and soundstages, as well as the informal buskers' stages on street corners and in subway stations. They also became part of a dance vocabulary for freestyle dancers. Again, Soul Train provided a model.

The Soul Train Line, instituted when the show began syndicated broadcast from Los Angeles in 1971, ${ }^{29}$ was a featured segment, nearly as anticipated every week as the featured guest. Christopher P. Lehman writes, "The Soul Train Line became key to Soul Train's rising viewership. As press coverage of the show accelerated midway through the first California season, reporters commented on the dances. The media attention, in turn, led to a rise in markets signing on to broadcast the series." ${ }^{\prime 30}$

Lehman sets the scene. In the typical Soul Train Line segment, two lines form, male and female, with the dancers facing each other and making an alleyway. "The crew [remove] the risers from the stage, and the dancers [form] four columns - two on each side of the stage [i.e., two complete Soul Train Line formations]." ${ }^{\prime 1}$ The boy and girl at the top of the line dance down the gauntlet, showing their best moves, and commanding fifteen to twenty precious seconds of on-camera time; meanwhile, each opposing couple in the line keeps time with a simple move, inching toward the spot when it will be their turn to style down the line. Each couple dances their own individualized freestyle (and, pointedly, improvised) moves, pulling from dances like the Robot, the Funky Chicken, the Electric Slide, the Boogaloo, the Funky Broadway, Locking, and others, in an age when one might have expected performances of a single, stable dance style in a more staged routine. Moves from these various dances are incorporated by the dancers but usually as a brief reference or gesture. The point in the dance pairs' solo highlight segment is to show their original choreography, not simply demonstrate mastery of the latest thing that everyone else knows. That is to say, dancers dip into a repertoire of recognizable dance moves, in linkages decided on in the moment but not with an absence of forethought. The moves adapt, extend, and comment (signify) on the set dances, in real-time response to the music and the environment. They embody, in short, techniques of improvisation in jazz. ${ }^{32}$

"Chameleon" is recognizable by its groove, played on the "bass" and locked in with the drums. ${ }^{33}$ This provides a background for virtuosic improvisation by the other instruments, a significant amount of which can be understood as a vocabulary of melody fragments, gestures, and riffs, improvisationally incorporated in creatively applied ways. This approach to improvisation has a long history in jazz. ${ }^{34}$ Indeed, swing-era big-band leader Jay McShann pointed to this technique to help explain the musical inventiveness of his young and upcoming 
alto saxophone player Charlie "Bird" Parker. Parker had studied extensively with Buster Smith, picking up from him an enormous catalog of "riffs" (short melodic fragments repeated as ostinatos and "stacked" on each other by various sections of the band). Despite the fact that McShann had a fine lead alto player in John Jackson, who was a fluent sight-reader, "When we did a head tune [i.e., an arrangement created orally, not written out], Bird phrased, and Bird set most of the riffs." ${ }^{35}$

\section{The Soul Train Gang}

The dancers made it into the ranks of the Soul Train Gang through highly competitive auditions. Standouts like Damita Jo Freeman, Jeffrey Daniel, Patricia Davis, Cheryl Song, Don Campbell, and, later, Jody Watley became minor stars in their own right. ${ }^{36}$ Although not paid (at least in the first several of the show's seasons), they became sought after by fans of their own.

As Don Cornelius mentions in a Soul Train retrospective interview, the Soul Train Line was not something he invented. "It was something that you could find in any house party in Chicago in the seventies, because it was something that was already popular in Chicago. If you went to a house party in Chicago," he continued,

somebody would always organize or instigate a line. And when I got control of the show itself, one of the things I thought I would try for television would be a line, which became infamous as a Soul Train Line. But I pretty much lined the kids up and showed them how to do it. But I didn't invent it. It was borrowed from what we had done at house parties in Chicago for many, many, many years. ${ }^{37}$

Cornelius was likely referring to the Stroll.

The Stroll, a line dance that emerged in 1956-the year Cornelius turned twenty - and that gained momentum as a fad dance through the early 1960s, established a format that was directly applicable to the Soul Train Line, ${ }^{38}$ although the pace was entirely different (the Stroll was danced at a slow-drag tempo). ${ }^{39}$ I want to focus on the Stroll between the lines, the couple performing, as Tom Nelson describes, "a 'shine' routine as they proceed down the line with all eyes on them." "40 The point of the routine, as in the Soul Train Line, was to emerge from the sameness of the dance chorus, to evoke delight and maybe a bit of envy, from your fellow dancers at the creativity of your moves and your attitude. The range of improvisatory moves was quite confined, compared to the Soul Train Line some fifteen years later ${ }^{41}$; nevertheless, both dance segments depended on the interplay of structured steps by the group and subsequent improvisation by the highlighted pair, in what can be understood as Signifyin $(\mathrm{g})$ on those basic steps. ${ }^{42}$ 
One notable feature that the Stroll shared with the Soul Train Line-and with perhaps dozens of other social dances that emerged in the 1960s-was a shift to "apart" dancing (a trend that would become a wholesale change with the Twist craze, shortly thereafter): dances that assumed a partner but that did not incorporate touching, embracing, holding hands - connected partners - as had dominated social dance styles in the United States throughout the century. ${ }^{43}$ Once the Twist became an international dance craze, as the Eisenhower era gave way to Kennedy's New Frontier, there was no backward glance at the full-skirted, twirling, and partner-supported acrobatic dances of earlier days. Overnight, touchless, "apart" couple dances became hip in an ever-expanding array that included the Mashed Potatoes, the Pony, the Monkey, the Watusi, the Swim, and others. The vast majority of the new dances appeared and were popularized in black communities, only to be embraced (and appropriated) by the (white middle-class) mainstream. The succession of "apart" dances continued through the next several decades. The necessity of even a putative partner gradually faded, and dancers - with assumed partner or not - could move independently or in interaction with the crowd. In the context of the Soul Train Line, this meant, gradually, that gendered pairs may or may not refer to each other's stylized moves as they soloed or duet-danced for the camera. ${ }^{44}$

\section{Dancing's Impact on Funk}

Dancing apart in the Line-and eventually dancing solo-allowed the dancers to clarify and control the composition of their role of joining the musicians - or their surrogate, the recording — as a temporary member of the group, in effect "sitting in." As mentioned above, the eclecticism of the Soul Train Line can be seen as a kind of improvisation - freestyling - that Soul Train Gang dancers incorporated into solo performative dancing routines as well. Damita Jo Freeman joined James Brown onstage in the spring of 1973 as Brown performed a live version of "Superbad" with his band, the JB's. ${ }^{45}$

In the segment, Brown, normally a ball of dancing fury onstage, stands slightly to the side and conducts the band, smiling admiringly as Damita Jo dances a routine liberally peppered with Robot, Locking, and Kung Fu moves. (The show, on February 11, 1973, aired a half year after Bennie Maupin saw the Robot at Wattstax and a half year before the recording of "Chameleon," in August 1973; the Jackson 5 performance would come three months later.) ${ }^{46}$

It is easy to share Brown's fascination with Damita Jo's dance. Musically, the segment is largely an extended break, prefiguring what will soon become, at the hands of Bronx party deejays, a transformative technique of extending breaks on records using two copies on separate turntables by resetting one record to the beginning of the break while the identical record plays through it on the second turntable. Damita Jo's dance incorporates the Robot sequence twice, as the song elongates and (finally) heads to the verse; the Robot moves are folded into her pastiche of locking moves. The interspersed Black Power 
salutes and martial gestures reinforce lyrical references to "superbad" power and strength.

The overall effect would seem to point to two possible explanations of her string of moves, particularly the reprise of the Robot sequence; either Freeman's routine is choreographed and she must restart it when the music goes unexpectedly long, or she draws from a dance move vocabulary, a menu of expressive movements to be used, adapted, and reordered in highly improvisatory ways, as noted in the duals of funk dance and jazz. But there is a third possibility. Dance scholar Jonathan David Jackson calls attention to "African American vernacular dancing in its original socio-cultural contexts, where there is no division between improvisation and composition. In black vernacular dancing, improvisation means the creative structuring, or the choreographing, of human movement in the moment of ritual performance. ${ }^{\prime 47}$

Soul Train Gang dancer and, later, R\&B recording artist Jody Watley illustrates the fluidity between choreography and improvisation on the Line in a retrospective interview included in the DVD compilation The Best of Soul Train. "Often we'd come up with routines just on the spot," she explains. "If you knew the camera was coming, it's like, 'Okay, Robot.' Or the camera's coming around again: 'Let me do something else.' Or you may to start doing a movement and your partner would start hitting the same movement, too. So it was very spontaneous." ${ }^{48}$

James Brown's funk song structures during the period encourage "in the moment" choreography. Built on a foundation of a single chord, relentlessly reinforcing the downbeat (the one) that signals the beginning of a two-measure pattern, Brown's grooves seem never to begin or end; they just keep cycling. ${ }^{49}$ Against this churning but stable backdrop, Brown's vocal interjections, as well as solo moments taken by certain highlighted instruments or horn punches, keep the moment fresh and vital. Just so, Damita Jo Freeman's dance assumes the groove but does not adhere to it. There is no need to tell a story and no need to fixate on any particular dance over a protracted time; a gesture, a suggestion, will do. Jonathan David Jackson contrasts this sensibility with ballet (and, by extension, earlier forms of European dance with a lengthy, progressive choreography, exemplified in baroque dance). "Explaining her process of witnessing an African dance company named Ko-Thi, the critic Joan Acocella observed that 'whatever I was hungry for . . . was Aristotelian form. This is a kind of Euro-American value: art as a parabola, with a beginning, middle and endinga certain kind of shape, with a certain complication in the middle... Mozartean development. ${ }^{" 50}$ Funk has a way of playing with these two notions, European and African based. James Brown's music from 1965 on seems improvisational even when the groove is very tightly knit, completely orchestrated. Whether this is true or not, one gets the impression that the riff is the only thing set in advance and that even the title or the lyrical subject occurs spontaneously and is only later grafted to the song itself. "Mother Popcorn" and "The Funky Drummer" (both 1969) seem like tossed-off phrases, perhaps in rehearsal, perhaps 
during the recording itself, that then are incorporated as the title of the songs and the theme of the lyrics. This impression is confirmed by Brown's drummer, Clyde Stubblefield, as he describes how "The Funky Drummer" came about:

We were being in the studio, just sitting around. I started off something and the bass player joined in. And then the guitar player come[s] in, and the whole instruments. And we just have a groove going. And so Brown comes in and says, "Hey! Let's make a song out of that." Said, "We already have the rhythm," and so he started singing. "I don't care," and then the horns come in, and we've got a song. Nobody planned it. There was no plan; there was just a groove that he started singing on.

[At that time] all his songs was a groove. And by the time I joined him, he had about three or four songs that were planned [i.e., arranged] songs. But I didn't play the planned songs, because I didn't want to. Jabo [John Starks] played on them, the other drummer. But mostly the drums I played were just a jam tune, where we'd be in the studio jamming before he got there. ${ }^{51}$ Note the similarity to John Jackson and Charlie Parker above.

The recordings, paradoxically, seem at once tightly composed ("choreographed") and improvised in the moment. The "Mozartean" development, the "complication in the middle," happens at the bridge - a shift to a contrasting harmony, with its own groove pattern and its own lyrical markers-and the break - the moment when all musicians drop out save one, for a couple of measures or an extended time..$^{52}$

To Jackson, the interpenetration of choreography (the composed) and improvisation (the spontaneous, the contingent) in African American popular dance happen both in real time on the dance floor and over time in the creation of new dance styles and traditions. "Decisive solutions in which new vernacular traditions are developed in different black communities, such as the emergence of the Lindy Hop in the 1930s and the development of breakdancing in the early 1980 s," Jackson writes, "appear at the same time that particular steps and forms are recast and recycled and principles of physical, spatial, aural, and qualitative action are passed on from one tradition to the next." ${ }^{53}$

As with funk music, so with funk dance; as with funk dance, so with Head Hunters.

\section{Dance, Funkiness, and Jazz}

Jonathan David Jackson, building on work by Albert Murray and Katherine Hazzard-Donald ${ }^{54}$ analyzes individual dancers' "processes" across two en- 
twined but separate fields of activity and meaning that he identifies as individuation and ritualization. Individuation strategies can be expressed as "repeating (to intensify the experience); braiding (to produce complex, interwoven dynamic contrasts); and layering (phrasing to create a sense of flow, juxtaposition, overlap, or continuity between actions). ${ }^{, 55}$ These strategies are present in Damita Jo Freeman's freestyling dance to James Brown's "Superbad," in the Soul Train Line dancers' moves generally, and in Michael Jackson's Robot performance in the "Dancing Machine" break.

Freeman, as we have seen, quickly shifts modes (braiding and layering), at times juxtaposing and at other times flowing from Robot to Kung Fu to Shimmy to Locking (and to unnamed moves and gestures of her own invention). Whether or not she repeats the Robot sequence as an intensification strategy (repeating), we recognize the repeat and mark it. Likewise, the Soul Train Line dancers frequently but not necessarily traverse down the line in short repeated gestures and figures (the dance equivalent to the jazz riff). The couples' moves may be coordinated or not, braided or not, to use Jackson's term. And Michael Jackson's robotic moves, with their seamless, paradoxical "personification" of a "mechanical man" character, present a case study in layering. Moreover, all of the segments flit between individuation and ritualization. All of them express intensely personal style while referring to the familiar step - and setting expected on the "hippest trip in America." Finally, all of them traverse a continuum between poles of performativity and participation: even Michael Jackson's performance converses with other Robot performances and performers since he had received pointers on the Robot from Soul Train Gang members. ${ }^{56}$

\section{Soul Train and Authenticating "Chameleon"}

Processes in funk dance coincide with similar processes in funk music and in jazz. The relationship of funk music and jazz should not surprise us. No less a funk figure than Fred Wesley, James Brown's musical director through the early 1970s — until he left to join Parliament-Funkadelic — has said that "I've always held the belief that funk and jazz are basically the same thing, with emphasis on different elements and playing with different attitudes." ${ }^{57}$ Wesley's own background as a jazz trombone sideman; his stint, beginning in 1978, with the Count Basie Orchestra; and his subsequent faculty position (2004-2006) in the jazz studies department in the University of North Carolina at Greensboro's School of Music add weight to his assessment from both poles of the funk-jazz continuum.

I have written in another context about Herbie Hancock's twofold attraction to the funk groove. ${ }^{58}$ In one sense, he wanted to capture funk's black populism, to reconnect, as a jazz player, with jazz's former comfortable relationship with young, working-class black life. In another sense, the thirty-three year old wanted to grasp funk's aesthetics, to understand a younger generation's music at a deep level. "When I heard [Sly and the Family Stone's] 'Thank you Falletin 
Me Be Mice Elf Agin' [1969], it just went to my core," he recalled in a 1999 interview. "I didn't know what [Sly] was doing. I mean, I heard the chorus but, how could he think of that? I was afraid that that was something I couldn't do. And here I am, I call myself a musician. It bothered me." 59 Playing material for the album, as it was developing, in small Bay Area dance clubs, Hancock was able to verify how well he was clicking with the aesthetics he wanted to internalize and with an audience he wanted to court. Bodies sweating on the dance floor let him know.

Those bodies did more than give him a rubric to grade his efforts, though. They participated musically. I want to return to Clyde Stubblefield's remarks about "The Funky Drummer": "mostly the drums I played were just a jam tune, where we'd be in the studio jamming before he got there." What Stubblefield describes is directly analogous to Jonathan David Jackson's assertion, referenced above, that in funk dance, there is "no division between improvisation and composition." Yet the product of this blended activity, the groove, itself is stable in "The Funky Drummer," as it tends to be in James Brown's 1970s-era music: an ostinato matrix, in which each member of the group plays a fraction of the total, seemingly placed on an endless "sample and hold" loop, whether on vinyl or played live. Where is the improvisation? While most analyses of James Brown's funk (including my own) ${ }^{60}$ direct their attention to the groove players' "fixed rhythmic group" role supporting Brown's "variable rhythmic group" improvisations, another "variable rhythmic group" of improvisers is at work: the focus of the music, in fact, even if their improvisatory contribution is not audible. The improvisatory action comes largely from the dancers themselves, interacting with the music in ways that make clear that the music itself is only part of the medium. Whether onstage, as Damita Jo Freeman is in the 1973 clip, or on the floor, as are the rest of the dancing audience, Soul Train's dancers embody in the moment and in expressive, externalized ways how they are experiencing the musicians; the improvising dancer is, in effect, "sitting in" with the band.

At this point, I must enter the realm of speculation. As a drummer, I understand two ways to get dancers on the floor to "dig in," to intensify their funky moves. The first is to strip away syncopated complications of the beat, bringing it down to just a solid bass drum landing on the downbeat and a sharp backbeat hit on the snare drum. The second is an opposite approach: play intensified syncopated figures, even avoiding the downbeat, and force the dancers to strengthen their moves to the basic time-inciting the dancers to supply the all-important one beat for me and my colleagues on the bandstand. Dancers, for their part, can do the same in reverse. At some point every night, it seems, some dancer eschews the fancy moves and starts landing-boom-on the one, and I have no choice but to go along. There is no way to replicate this relationship with a seated audience - at least, I have not found one. This dynamic relationship seems to have played a foundational role in the music etched onto vinyl as Head Hunters. 
Head Hunters became the iconic album of a growing resurgence of funkiness in jazz - an orientation to young black people dancing; this was the latest peak in an undulating historical relationship of dance with jazz, but it would not be the last. Although in some quarters jazz musicians consciously rejected funk's (and rock's) intrusions into their "pure" art practice, plenty of young musicians embraced a panoply of styles. As bassist and producer Marcus Miller explains in an interview, "It's just music, and the lines dividing these things aren't as thick as people think. ... Musicians coming from urban situations are exposed to all these kinds of music at one time, in equal amounts." ${ }^{.61}$ This eclecticism has found expression in myriad ways, from the acid jazz and jazz-funk movements, emanating originally from Britain's dance clubs, to revitalizations of New Orleans-style R\&B in jazz settings (e.g., the Dirty Dozens Brass Band and Los Hombres Calientes), as well as funk inflections by the generation of "young lions" who embraced jazz in the Wynton Marsalis slipstream. (Joshua Redman's "Jazz Crimes" and Jason Moran's "Planet Rock" give two divergent examples. Jason Moran's "Fats Waller Dance Party" collaboration with Meshell NdedgOcello at the new San Francisco Jazz Center provides a more recent example.) Swing rhythms are still assumed in jazz, but in practice jazz performers' exploration of funkiness, along a continuum from Afro-Caribbean to funk and hip-hop grooves, takes up an increasing, even dominant amount of time in a typical set.

The reciprocal influences of funk dance, funk music, and jazz were played out, became apparent, and were facilitated on the Soul Train soundstage, a show watched by "everyone" in young, urban black America, as Rickey Vincent reminds us. Those watchers - and dancers- present for Herbie Hancock's performance of "Chameleon," in effect, pronounced the piece funky. Part cultural touchstone, part dance classroom, Soul Train exerted a deep influence not only in funk but also in jazz through the medium of dance.

\section{Notes}

1. Herbie Hancock, Head Hunters, Columbia 88697843472, 2011 (1973). Because of some confusion in marketing the album, the official two-word title Head Hunters distinguishes it from the one-word name of Hancock's group, the Headhunters. The Headhunters, with and without Hancock, have continued to tour and record periodically ever since.

2. Although it is not my intention to catalog the jazz-funk stream within the larger fusion jazz movement, Head Hunters is routinely cited in discussions of mid-1970s fusion jazz as well as such later developments as acid jazz and contemporary jazz of the 1980s and 1990s and has become a touchstone for deejays across a variety of hip-hop trends. It also can be seen to hasten the coming showdown, in the $1980 \mathrm{~s}$, between the neoclassical jazz faction, represented by Wynton Marsalis, and fusion jazz generally. See Rafi Zabor and Vic Garbarini, "Wynton Marsalis vs. Herbie: The Purist and the Crossbreeder Duke It Out," Musician 77 (March 1985), reprinted in Keeping Time: Readings in Jazz History, ed. Robert Walser (New York: Oxford University Press, 1999, 339-51 (343).

3. The often-repeated show slogan entered the culture at some point in during its run. See also Rickey Vincent, Funk: The Music, the People, and the Rhythm of the One (New York: St. Martin's Griffin, 1996), 169. See also Christopher P. Lehman, A Critical History of Soul Train on Television (Jefferson, NC: McFarland \& Co., 2008).

4. Steven F. Pond, Head Hunters: The Making of Jazz's First Platinum Album (Ann Arbor: University of Michigan Press, 2010). The book considers Head Hunters from its position in a "web of affiliations," to adapt Georg Simmel's term (and Mark Slobin's usage of it), including jazz's earlier connections to funkiness through the "soul jazz" trend of the late 1950s and early 1960s. 


\section{Steven F. Pond}

As I point out in that monograph, Herbie Hancock's own history with soul jazz (e.g., "Watermelon Man," 1962) played a developmental role in his attraction to funk. See chapter 3, "At the Crossroads of Genre" (51-81), especially the sections "Fifties Funk Jazz to Seventies Funk" (62-66) and "Laying Down a Funk Groove" (66-78). See also the section "Hard Bop, Modal Jazz, and the Avant-Garde: Difference, Convergence, and Transcendence (84-90) in chapter 4, "The Pasts They Brought with Them" (83-115).

5. This is not to place Head Hunters alone in tapping this new audience. Indeed, Miles Davis's Bitches Brew (1970) had demonstrated the market potency for fusion. However, Head Hunters's sales outstripped all comers and outsold Davis's album by a factor of four to one.

6. Herbie Hancock, quoted in Zabor and Garbarini, "Wynton Marsalis vs. Herbie," 343.

7. This paper explores a stylistic and historical relationship between funk and jazz. This is not to disclaim other connections, pointedly funk's with disco and hip hop. I have chosen to narrow the focus to funk's relationship with jazz.

8. Bennie Maupin, interview with the author. See also Pond, Head Hunters, 73.

9. In fact, Head Hunters proved to be a hybrid of both funk and jazz, exploring musical elements, production techniques, and marketing strategies of both of them-and of avant-garde musics, pop, African, and diasporic musics. For more on this hybridizing, see Pond, Head Hunters.

10. Perhaps not coincidentally, the album got little airplay initially on jazz radio. The stations finally started playing tracks from the album only after the album's success seemed inevitable.

11. Hancock and his group played "Chameleon" on Soul Train early the next season on September 28, 1974.

12. Bennie Maupin, interview with the author, in Pond, Head Hunters, 141.

13. Herbie Hancock, interview with the author, in Pond, Head Hunters, 142.

14. The dance's beginning has been attributed broadly to Charles "Robot" Washington around 1967.

15. The album was released on October 13, 1973. By the summer of 1974, it was well on its way to becoming the first jazz album, under the newly designated Billboard Jazz Albums chart, to achieve platinum status $(1,000,000$ copies sold $)$.

16. Soul Train began in Chicago (1970) as a locally broadcast after-school show. Beginning with the 1971-1972 season, the show became a weekly syndicated show, shown late Saturday mornings. The local Chicago broadcast continued as before. Soul Train, then, was two shows, each with its own content, for several years.

17. Vincent 1996: 169. See also Lehman 2008.

18. Other prominent local and regional shows were hosted during the 1950s, 1960s, and 1970s by Lloyd Thaxton (Los Angeles) and Buddy Deane (Baltimore). As a teenager, I religiously watched The Bill Rase Show after school in Sacramento, California, and I surmise that many such local shows were broadcast at the time.

19. Watching Soul Train was instructional for the audience, too, and resonates with Marya Annette McQuirter's discussion (in “Awkward Moves: Dance Lessons from the 1940s," in Dancing Many Drums: Excavations in African American Dance, ed. Thomas F. DeFrantz [Madison: University of Wisconsin Press, 2002], 81-103) of learning to dance in the home in the 1940s. McQuirter explodes "the widespread notion that all black people dance well," a notion promulgated as an effect of racial segregation in which white observers would come into observational contact only with accomplished dancers (20-21). Dancing, a deeply important social activity, was often taught in the home by older siblings or other relatives, often of the same sex. "[Home] lessons included not only how to dance but how to create a physical and psychic intimacy that was often more difficult in other settings" (95). Soul Train in the 1970s provided these lessons at a safe distance if one wanted to watch alone as well as avenues to model both current dance moves and currently hip comportment and "physical and psychic intimacy" for friends watching together.

20. From its beginnings as a local Chicago show, Soul Train's show executives scouted nightclubs for dancers and recruited them from local high schools in a rigorous audition process. The practice in Soul Train's nationally syndicated weekly show, emanating from Los Angeles, was slightly different. There, in addition to auditions run by the show's choreographer, Clinton Ghent, Cornelius and Ghent and show coordinator Pamela Brown visited dance clubs and meetings of youth groups and organizations "all over Los Angeles to seek teenagers for the program" (Lehman, A Critical History of Soul Train on Television, 29, 55).

21. Kevin Phinney, Souled American: How Black Music Transformed White Culture (New York: Billboard Books, 2005), 243.

22. Brian Ward, Just My Soul Responding: Rhythm and Blues, Black Consciousness, and Race Relations (Berkeley: University of California Press, 1998), 420. Slaughter had earned his stripes earlier as a promotion man for Columbia Records. For a discussion of his central role in the success of Head Hunters (1973), see Pond, Head Hunters, 171-73.

23. Michael Jackson's Robot break in the Jackson 5's performances of "Dancing Machine" (1973), performed on Soul Train on November 3, 1973; see http://www.youtube.com/ watch? $=$ uJYzlGzTaZw. 
24. The lyrics open the door for ambiguity. Although "filled with Space Age design," the dancer is a "sexy lady." Or is she an actual automaton, who, "at the drop of coin, comes alive?"

25. The Robot was alternatively known as the Marionette.

26. The possibility exists that the mic was meant to pick up one of the performer's voices, but this is unlikely. Although some performers did perform live (James Brown was known for this), the common practice was to lip-synch performances for the show. Nevertheless, the Jackson 5 coordinate their mouthing to the recording with such precision that it is almost impossible to determine. Their audible handclaps at the song's introduction $(0: 18)$ —not on the recording — make it plausible that they could have been performing live vocals to a recorded track stripped of the studio vocals. But Michael jerks his head back in the middle of a word with no loss of sound the vocal on the mic ("doin'," in the line, "She knows just what she's doin"" [1:11]).

27. In fact, the Robot had already appeared on Soul Train. Lehman (A Critical History of Soul Train on Television, 84) reports that dancers interviewed on the first syndicated show discussed popular dances moment, including the "Mechanical Man." Also, Damita Jo Freeman's Robot moves during a James Brown performance (February 10,1973) predates the Jackson 5's segment by several months. See below for a more detailed look at this segment.

28. Don Campbell, originator of the Lockers dance troupe, is generally credited with originating the Campbell Walk and Locking, both in the late 1960s. See the chronology by Steffan "Mr. Wiggles" Clemente, a second-wave member of the Rock Steady Crew, Electric Boogaloos, and Universal Zulu Nation, at http://www.mrwiggles.biz/hip_hop_dance.htm. At the time he formed the Lockers with dancer/choreographer Toni Basil, Campbell was a regular on Soul Train (Lehman, A Critical History of Soul Train on Television, 78).

29. According to Lehman (A Critical History of Soul Train on Television, 74).

30. Lehman, A Critical History of Soul Train on Television, 74. A retrospective nine-DVD compilation, The Best of Soul Train, features several memorable performances of the Soul Train Line as well as segments of individual dancers. Producer and host Don Cornelius, in an interview, said that the Line was part of the show "from the very beginning" but does not specify if he is referring to the beginning of the syndicated version. See The Best of Soul Train (nine-DVD set), prod. and ed. Ralph Quatrucci (Fairfax, VA: Time Life/dist. Direct Holdings Americas, Inc., 2010).

31. Lehman, A Critical History of Soul Train on Television, 73. See, for example, the Soul Train Line dancing to War, "The Cisco Kid," episode 45, disc 2, original broadcast January 6, 1973.

32. On signifyin(g) in jazz, see Pond, Head Hunters, especially chapter 2, "'An African Thing': Aesthetics and Identity in Head Hunters" (31-50). See also Robert Walser, "Out of Notes: Signification, Interpretation and the Problem of Miles Davis," Musical Quarterly 77, no. 2 (Summer 1993): 345, and Gary Tomlinson, "Cultural Dialogics and Jazz: A White Historian Signifies," Black Music Research Journal 22, no. 1 (2002).

33. The low bass notes in the signature groove are played on synthesizer, not electric bass. Bassist Paul Jackson instead plays an answering "guitar" figure à la James Brown's Alphonso "Country" Kellum or Phelps "Catfish" Collins.

34. See, for example, chapter 4, "Getting Your Vocabulary Straight: Learning Models for Solo Improvisation," in Paul Berliner, Thinking in Jazz: The Infinite Art of Improvisation (Chicago: University of Chicago Press, 1994).

35. Scott DeVeaux, The Birth of Bebop: A Social and Musical History (Berkeley: University of California Press, 1997), 188.

36. Several of the young dancers on Soul Train went on to professional careers as dancers or choreographers (Damita Jo Freeman, Don Campbell, Patricia Davis, and Jeffrey Daniel). Jeffrey Daniel and Jody Watley formed the core of the vocal group Shalimar. Watley went on to a solo R\&B singing career. Daniel later worked as a choreographer on Michael Jackson's Bad music video (1987) and has remained active as a producer and choreographer. Don Campbell formed the seminal hip-hop dance troupe the Lockers.

37. Quatrucci, The Best of Soul Train.

38. "The Stroll is danced in two parallel lines, with men on one side and facing their ladies across the divide [i.e., the same format as the Soul Train Line]. A simple basic step-pattern is executed in such a fashion that the line advances one pace with each pattern worked. Individuals at the head end pair up and perform a 'shine' routine as they proceed down the line with all eyes on them, which at the end they separate and rejoin their lines. Then the next couple pairs up and makes their way down the line. Meanwhile, everyone moves in-place to the music" (Tom L. Nelson, 1000 Novelty and Fad Dances [Bloomington, IN: AuthorHouse, 2009], 215).

39. Key recordings for the Stroll included "C. C. Rider" (1957) by Chuck Willis and Fats Domino's "I Want to Walk You Home" (1959) and "Walking to New Orleans" (1960); a song called "The Stroll" became a hit in 1958 (released December 30, 1957) for the Diamonds, recorded at the urging of Dick Clark. The song peaked at number 5 on the Billboard Hot 100 chart.

40. Nelson, 1000 Novelty and Fad Dances, 215.

41. For an example of just how confined that range could be, see "The Original Stroll—1958," a preserved segment of white teenagers dancing on a local dance show in Idaho, http://www. 
youtube.com/watch? $v=U r G L N t Z 0 r E g$. I danced the Stroll as a preteen at about this time; kids prided themselves on going beyond these basic steps.

42. See Henry Louis Gates Jr., The Signifying Monkey: A Theory of African-American Literary Criticism (New York: Oxford University Press, 1988). Kyra Gaunt's book on black girls' jump-rope games ties Gates's work directly to dance movement prepared in the game of Double Dutch. See Kyra D. Gaunt, The Games Black Girls Play: Learning the Ropes from Double-Dutch to Hip-Hop (New York: New York University Press, 2006), 152.

43. Although not within the scope of this paper, I find it interesting that the Stroll appeared at a moment when connected dance (whether the Lindy Hop or one of its variants) was reaching a heightened level of intensity and just prior to its virtual disappearance with the advent of the Twist and its host of related dances, around 1960. Indeed, considering many aspect of the times - dance's long erotic role of sublimating and initiating sexual contact, the sexualization of the American teenager in the 1950s and early 1960s, the shifting roles for women in the workplace, and the availability of oral contraception beginning in 1960 - the why of the move away from touch dancing seems worthy of sustained study.

44. By the 1982-1983 season, the orientation of the Line had abandoned an assumption of couples dueting. "The change from couples to single individuals dancing down the line marked a major break from Soul Train tradition. Over the years not every couple had danced down the Line as a cohesive unit. In the show's early seasons, Damita Jo Freeman sometimes danced the 'Robot,' while her partner made his own moves, and Jimmy Foster's 'Locking' occasionally clashed with a female partner's understated shuffling" (Lehman, A Critical History of Soul Train on Television, $138-39)$.

45. Although most song performances on Soul Train were lip-synched, a handful of artists, James Brown among them, preferred to perform live.

46. See The Best of Soul Train, disc 2. The segment can also be found online, although misidentified as being from 1970, at http://www.youtube.com/watch? $\mathrm{v}=\mathrm{xbLDaQ1VhFM}$.

47. Jonathan David Jackson, "Improvisation in African American Vernacular Dancing," Dance Research Journal 33, no. 2 (Winter 2001/2002): 44 (emphasis added).

48. Jody Watley, interviewed on Quatrucci, The Best of Soul Train, disc 3.

49. For an extended discussion of funk groove construction in James Brown's and Sly Stone's music, see Pond, Head Hunters, 66-78.

50. Jackson quotes from Joan Acocella, "Coming to Grips with the 'Other," in Looking Out: Perspectives on Dance and Criticism in a Multicultural World, ed. David Gere (New York: Schirmer Books, 1995), 46.

51. Clyde Stubblefield, interviewed by Marley Marl, 2008, http://www.youtube.com/ watch? $=\mathrm{V}=\mathrm{Z} 3 \mathrm{xSXc} 1 \mathrm{vy} 5 \mathrm{I}$.

52. For an example of a bridge (in this case, an extended one), see "Make It Funky" (1:404:04), http://www.youtube.com/watch?v=RjJ0XTofXO4. For an example of a short break, see Brown's Soul Train performance of "Get on the Good Foot" (1:49-1:56), http://www.youtube. $\mathrm{com} /$ watch? $\mathrm{v}=1 \mathrm{~N} 5 \mathrm{jY00z}$ Sk\&feature=related. The segment can also be found on The Best of Soul Train, disc 2 (1:15:51-1:15:59). For an example of an extended break, see "The Funky Drummer" (5:35-5:54), http://www.youtube.com/watch?v=dNP8tbDMZNE.

53. Jonathan David Jackson, "Improvisation in African American Vernacular Dancing," 41. Emphasis in the original.

54. Albert Murray, Stomping the Blues (New York: Da Capo, 1976); Katrina Hazzard-Donald (writing as Katrina Hazzard-Gordon), "Afro-American Core Culture Social Dance: An Examination of Four Aspects of Meaning," Dance Research Journal 15, no. 2 (Spring 1983): 21-36. 46

55. Jonathan David Jackson, "Improvisation in African American Vernacular Dancing,"

56. Discussing Jackson's incorporation of the Robot on the 1973 "Dancing Machine" performance, Lehman writes, that the Jackson 5 "were the first performers to borrow dance steps from the program's dances, thus giving the Gang legitimacy as dancers" (84).

57. Fred Wesley Jr., Hit Me, Fred: Recollections of a Sideman (Durham, NC: Duke University Press, 2002), 191.

58. Pond, Head Hunters.

59. Rafi Zabor and Vic Garbarini, "Wynton Marsalis vs. Herbie Hancock: The Purist and the Crossbreeder Duke It Out," in Robert Walser, Keeping Time: Readings in Jazz History (New York: Oxford University Press, 1999), 343 (vocal emphasis in the original).

60. See, for example Pond, Head Hunters, 65-70. See also David Brackett, "James Brown's 'Superbad' and the Double-Voiced Utterance," in Interpreting Popular Music (Cambridge: Cambridge University Press, 1995), 108-56, and Olly Wilson, "The Significance of the Relationship between Afro-American Music and West African Music," The Black Perspective in Music 2 (Spring 1974): 3-22.

61. Ben Sidran, Talking Jazz: An Oral History (24-CD set) ([S.I.]: Unlimited Media, 2006). 